\title{
PENGEMBANGAN MODUL BRAILLE PENDIDIKAN KESEHATAN REPRODUKSI BAGI REMAJA TUNANETRA
}

\author{
Istiqomah $^{1}$, Ro' $^{\prime}$ fah $^{2}$ \\ ${ }^{1}$ Mahasiswa Pasca Sarjana UIN Sunan Kalijaga \\ ${ }^{2}$ Universitas Islam Negeri Sunan Kalijaga Yogyakarta
}

\section{Article Info \\ Article history: \\ Jun $12^{\text {th }}, 2020$ \\ Aug $20^{\text {th }}, 2020$ \\ Oct $26^{\text {th }}, 2020$}

\section{Keyword:}

Modul Braille

Kesehatan Reproduksi

Remaja Tunanetra

\begin{abstract}
Penelitian dilaksanakan dengan tujuan untuk mengetahui pengembangan modul Braille pendidikan kesehatan reproduksi, mengetahui hasil validasi ahli dan praktisi serta mengetahui kelayakan modul Braille pendidikan kesehatan repoduksi bagi remaja tunanetra. Metode yang digunakan dalam penelitian ini adalah menggunakan metode research and development/ R\&D. Penelitian research and development digunakan untuk menghasilkan produk tertentu dan menguji efektifitas produk tersebut. Subjek penelitian adalah 1 ahli media dan ahli materi, 1 guru bimbingan konseling, 3 siswa tunanetra, 6 peer reviewer. Hasil penelitian disimpulkan bahwa presentase tertinggi dengan nilai $98,18 \%$ adalah guru bimbingan konseling, sedangkan hasil terendah diperoleh nilai presentase $88,16 \%$ adalah hasil dari peer reviewer. Selanjutnya hasil penilaian presentase dari ahli materi $95 \%$, ahli media Braille dengan hasil perolehan presentase sebesar $90 \%$, kemudian hasil penilaian terakhir oleh siswa dengan perolehan presentase sebesar $88,33 \%$. Secara keseluruhan hasil presentase memperoleh kategori sangat baik, karena hasil presentase berada dalam penilaian interval yaitu $80 \%-100 \%$ dengan kategori sangat baik maka pengembangan modul Braille pendidikan kesehatan reproduksi layak digunakan untuk pembelajaran kesehatan reproduksi bagi remaja tunanetra.
\end{abstract}

\section{Corresponding Author:}

Istiqomah $^{1}$

Mahasiswa Pasca Sarjana UIN Sunan Kalijaga

Email: Istiqomahqoqom11@gmail.com

\section{Introduction}

Persatuan tunanetra indonesia (PATUNI) menjelaskan tunanetra, mereka yang tidak mampu melihat total sampai mereka yang mampu melihat sisa penglihatannya akan tetapi mereka tidak mampu menggunakan penglihatan tersebut untuk membaca tulisan dengan ukuran 12 point dengan cahaya normal meski sudah dibantu dengan menggunakan kacamata (Mutiara Mir'atannisa, 2017). Tunanetra dapat terjadi karena dua faktor yaitu faktor internal diantaranya berhubungan dengan keadaan bayi selama masih dalam kandungan sedangkan faktor eksternal terjadi setelah bayi tersebut dilahirkan (Somantri, 2012).

Keterbatasan yang tunanetra alami menjadi tantangan yang besar bagi orang tua dan guru dalam memberikan pemahaman terkait pendidikan kesehatan reproduksi (Lukfiyanti, 2020). Menurut (Lutfi Ghazali, 2009) strategi yang dapat digunakan untuk meningkatkan pemahaman serta sikap remaja tunanetra adalah dengan pendidikan kesehatan reproduksi. Pemberian pendidikan kesehatan reproduksi bagi remaja tunanetra menurut (Aziz, 2014) adalah agar memiliki sikap serta tingkah laku yang dapat bertanggung jawab serta 
remaja tunanetra tidak merasa bingung dengan perubahan yang terjadi pada diri mereka baik secara psikologis maupun biologis. Informasi yang tepat serta akurat menjadi hal penting yang harus diperhatikan dengan baik.

Informasi mengenai kesehatan reproduksi perlu disampaikan kepada remaja tunanetra (Mustafidah, 2018). Hak-hak penyandang disabilitas yang tertera dalam Konvensi Hak-hak disabilitas yang tertera pula dalam undang-undang Republik Indonesia no. 19 tahun 2011 tentang pengesahan konvensi hak-hak penyandang disabilitas telah menegaskan bahwa tidak ada diskriminasi dalam bentuk apapun bagi penyandang disabilitas termasuk dalam hal pendidikan kesehatan (Pamungkas dkk., 2019).

Mengatasi masalah kesehatan reproduksi tentu memiliki cara tertentu disetiap negara. Negara berkembang mengatasi masalah kesehatan reproduksi dengan menggunakan setting program, program ini berbasis sekolah, media massa, komunitas, tempat kerja, dan juga fasilitas kesehatan (Speizer dkk., 2003). Menurut (Hakim, 2008) berpendapat bahwa program sekolah tentu sangat efektif meskipun hasil yang akan diperoleh memiliki waktu yang panjang tetapi sekolah tetap menjadi tempat belajar kesehatan reproduksi yang terarah.

Pendidikan kesehatan reproduksi remaja tunanetra menjadi salah satu cara yang dapat mencegah dari masalah seputar kesehatan reproduksi (Suparyanti dkk., 2020). Sekolah menjadi tempat yang paling banyak waktu dihabiskan oleh remaja tunanetra. Sekolah juga menjadi tempat yang paling tepat untuk memperoleh informasi kesehatan reproduksi. (Rohani dkk., 2020) berpendapat bahwa pengetahuan pendidikan kesehatan reproduksi tepat dilakukan di sekolah juga agar informasi yang diberikan kepada remaja tunanetra dikemas sesuai dengan aturan pendidikan yang wajar dan norma-norma sosial yang berlaku.

MTs Luar Biasa Yayasan Kesejahteraan Tunanetra Islam Yogyakarta menjadi tempat yang tepat sebab mereka belum menerapkan pendidikan kesehatan reproduksi sesuai dengan kurikulum yang digunakan. Hasil wawancara dengan Sa'adah menyatakan "belajar kesehatan reproduksi banyak dilakukan melalui internet saja atau sekedar bertanya kepada saya apa yang ingin mereka ketahui" berdasarkan pernyataan tersebut pelajaran kesehatan reproduksi dilakukan dengan diskusi antara murid dengan guru tanpa landasan materi yang pasti dan murid juga lebih banyak mengakses informasi melalui internet. Keterbatasan materi tersebut menjadi alasan peneliti untuk mengembangkan media Braille kesehatan reproduksi. Peran media pembelajaran sangat penting artinya terhadap proses pembelajaran, intinya adalah sebagai jembatan bagi pendidik dan peserta didik, sebagai alat bantu untuk menjelaskan materi atau informasi yang sulit untuk dipahami dan juga media yang bisa menarik minat belajar peserta didik (Indriastuti, 2015).

Media Braille dipilih sebab materi-materi yang membutuhkan visualisasi dapat digambarkan didalam modul Braille. Media Braille menjadi pelengkap informasi mengenai kesehatan reproduksi yang diberikan melalui lisan atau audio (Lutfi Ghazali, 2009). materi-materi yang disajikan didalam modul Braille berupa hubungan sosial remaja tunanetra, dan memuat materi yang berkaitan dengan kesehatan reproduksi.

\section{Method}

Penelitian dilaksanakan dalam bentuk riset dan pengembangan (research and development/ R\&D). Menurut (Sugiyono, 2010) penelitian research and development digunakan untuk menghasilkan produk tertentu dan menguji efektifitas produk tersebut. Hasil produk dilakukan melalui tahapan assessment terlebih dahulu untuk menganalisis kebutuhan serta uji coba manfaat produk untuk publik, kemudian efektifitas produk juga harus melalui tahapan penelitian. Pendapat (Hermawan, 2019) menyatakan penelitian R\&D di bidang pendidikan dan sosial, produk dapat dihasilkan dalam berbagai bentuk diantaranya materi, media, alat atau model layanan yang dapat digunakan untuk mengolah permasalahan dalam berbagai dimensi.

Penelitian ini dikembangkan dengan prosedur sesuai dengan ADDE (Analysis, Design, Deveopment, Implementation And Evaluation) (Winarni, 2018). Pelaksanaan penelitian ini bertujuan hanya sebatas uji kualitas modul. Empat tahapan pengembangan yang dilakukan didalam penelitian menurut (Sumiati dkk., 2018) yaitu Tahap Analisis :

Pada tahap analisis dilakukan beberapa analisis seperti analisis kebutuhan sebagai dasar pengembangan modul Braille kemudian analisis karakteristik siswa pada metode belajar yang digunakan, analisis kurikulum sesuai dengan kompetensi inti dan kompetensi dasar sebagai tujuan pengembangan modul sehingga menghasilkan indikator pencapaian yang menghasilkan bahan materi.

Tahap Desain :

Pada tahap desain ini dilakukan rencana modul Braille seperti kerangka modul, penentuan sistematika penulisan modul, merancang jenis evaluasi sebagai uji pemahaman materi.

Tahap Pengembangan :

Tahapan yang dilakukan dalam pengembangan modul Braille diawali dengan menganalisis masalah pendidikan kesehatan reproduksi yang dibutuhkan remaja tunanetra kemudian mencari literatur serta pengumpulan data dilanjutkan dengan desain produk kemudian masuk pada tahapan validasi desain oleh dosen pembimbing dilnjutkan revisi produk. Pembuatan produk dilakukan setelah revisi produk yang akan diuji oleh ahli media, ahli materi, guru bimbingan konseling dan peer reviewer. Produk akan kembali direvisi 
sesuai dengan saran dari validator kemudian diuji keterbacaan modul Braille kepada siswa tunanetra. Modul Braille selanjutnya direvisi kembali sehingga menghasilkan produk akhir yang dapat digunakan.

Tahap Evaluasi :

Pada tahapan evaluasi ini berdampingan dengan tahap pengembangan modul agar memahami kualitas dan umpan balik modul bagi pengguna atau siswa kemudian dianalisis segi materi, media serta tanggapan siswa tunanetra MTs Luar Biasa Yaketnis Yogyakarta sebagai pengguna modul Braille.

Penilaian menggunakan konservasi skor dengan kriteria penilaian lengkap kemudian untuk mempermudah bacaan penjumlahan hasil menggunakan persamaan berikut ini (Sudijono, 2010):

Tabel 1. Skala Presentase Penilaian Kualitas Produk.

\begin{tabular}{|r|l|l|}
\hline \multicolumn{1}{|l|}{ No } & Interval & Kriteria \\
\hline 1. & $81 \%-100 \%$ & $\mathrm{SB} /$ sangat baik \\
2. & $61 \%-80 \%$ & $\mathrm{~B} /$ baik \\
3. & $41 \%-60 \%$ & $\mathrm{C} /$ cukup \\
4. & $21 \%-40 \%$ & $\mathrm{~K} /$ kurang \\
5. & $0 \%-20 \%$ & SK/sangat kurang \\
\hline
\end{tabular}

\section{Results and Discussions}

Modul Braille pendidikan kesehatan reproduksi menjadi hasil produk penelitian. Alasan tersebut sebab remaja tunanetra menggunakan sentuhan dan pendengaran untuk belajar (Friend \& Bursick, 2012). Model pengembangan yang digunakan dalam penelitian ini adalah ADDIE (Analysis, Design, Development, Implementation, And Evaluation). Pembatasan dalam penelitian ini adalah hanya dilakukan tanpa ada tahap implementasi. Tahapan-tahapan yang dilakukan dalam penelitian ini adalah:

Tahap Analisis :

Pada tahapan analisis akan dilakukan analisis kebutuhan belajar, analisis materi pokok dalam pengembangan modul, dan analisis kurikulum pendidikan kesehatan reproduksi yang digunakan.

Analisis Kebutuhan Belajar :

Beberapa Aspek tersebut perlu diperhatikan sebagai gambaran kebutuhan remaja pada umumnya dan juga remaja tunanetra. Menurut (Ali dkk., 2004) Aspek dari kesehatan remaja terdiri dari lima bagian yaitu persepsi tentang masalah kesehatan remaja, komunikasi interpersonal tentang perubahan selama masa remaja, perilaku mencari informasi, pengetahuan yang ada tentang PMS, minat memperoleh pengetahuan untuk masalah yang diidentifikasi dan saluran yang disarankan untuk informasi, pendidikan dan komunikasi.

Kondisi tunanetra menyebabkan remaja memiliki beberapa keterbatasan. Ada tiga keterbatasan yang dialami tunanetra yaitu keterbatasan dalam lingkup keberagaman pengalaman, keterbatasan berinteraksi dengan lingkungan dan keterbatasan berpindah tempat (Trumbul dkk., 2013). Keterbatasan tersebut seharusnya tidak menghalangi remaja tunanetra untuk memperoleh informasi kesehatan reproduksi. Remaja dapat menerima pendidikan kesehatan reproduksi dari berbagai sumber, termasuk pendidikan formal (misalnya, sekolah) dan pendidikan informal (misalnya, orang tua, teman sebaya, dan media) (Li dkk., 2013).

Pendidikan kesehatan reproduksi, melalui sekolah atau orang tua, merupakan langkah penting dalam mempromosikan perilaku seksual yang lebih aman di kalangan remaja (Dubarstein Lindberg dkk., 2000). Mereka harus memiliki pengetahuan yang benar pada bidang pendidikan kesehatan reproduksi (seksualitas subjek materi pendidikan) (Adegbenro dkk., 2006). Remaja membutuhkan informasi mengenai kesehatan reprouksi untuk mendapatkan perspektif baru tentang kehidupan remaja yang harus terpenuhi (AwusaboAsare dkk., 2006).

Berdasarkan analisis kebutuhan belajar siswa tunanetra MTs Luar Biasa A Yaketunis Yogyakarta buku atau modul Braille pendidikan kesehatan reproduksi belum ada sebab pembelajaran biasa dilakukan hanya tanya jawab mengenai keresahan tentang reproduksi yang ditanyakan kepada guru bimbingan konseling atau siswa akan mencari materi kesehatan reproduksi melalui internet.

Analisis Materi :

Bukti dari studi tentang pendidikan SRH (Sexuality and Reproductive Health) untuk remaja di seluruh dunia menunjukkan bahwa program yang efektif memiliki dampak mengurangi informasi yang salah dan menambah pengetahuan yang akurat, mengklarifikasi dan memperkuat nilai-nilai dan sikap positif, meningkatkan keterampilan yang diperlukan untuk membuat keputusan yang tepat dan menindaklanjuti, Meningkatkan persepsi tentang kelompok sebaya dan norma sosial (Wahba \& Roudi-Fahimi, 2012). Materi pembahasan yang terdapat pada modul Braille bertujuan untuk mengurangi kesalahan informasi. 
Materi-materi yang disajikan didalam produk modul Braille mengenai hubungan sosial remaja tunanetra, kesehatan reproduksi dan perubahan-perubahan yang terjadi pada remaja tunanetra. Pada produk modul Braille juga membahas mengenai pelecehan seksual sebab, remaja yang mengalami disabilitas sangat rentan terhadap terjadinya pelecehan seksual sehingga bisa berakibat terjadinya kehamilan yang tidak diinginkan serta terinfeksi penyakit menular HIV dan penyakit menular lainnya (M. Denno dkk., 2015).

Analisis Kurikulum :

Analisis kurikulum dilaksanakan mengacu pada penjelasan yang dijabarkan dalam Kompetensi Inti (KI), Kompetensi Dasar (KD), dan juga tujuan pembelajaran serta pencapaian siswa. Kurikulum yang digunakan oleh MTs Luar Biasa A Yaketunis Yogyakarta adalah kurikulum 2013. Materi yang ditawarkan didalam modul Braille adalah hubungan sosial remaja tunanetra, hubungan romantis, kesehatan reproduksi, dan gangguan penyakit seksual.

Tahap Perencanaan :

Penyusunan kerangka dari isi modul menjadi bagian tahapan perencanan. Sumber-sumber pustaka serta kumpulan referensi dilaksanakan dalam tahapan design. Peneliti menggunakan sumber pustaka melalui buku buku kesehatan reproduksi, buku paket IPA SMP/MTs, jurnal atau artikel, kemudian sumber pusaka melalui internet. Gambaran keseluruhan yang disediakan dalam modul braille melalui kerangka isi modul pendidikan kesehatan reproduksi. Tahapan penyusunan modul terdapat tiga bagian yaitu pendahuluan, isi dan penutup (Nasional, 2008). Menurut (Susilana \& Riyana, 2007) Desain awal modul pada bagian pendahuluan disesuaikan dengan kebutuhan siswa karena tidak semua media dapat memenuhi kebutuhan semua tingkatan usia. Oleh sebab, itu hasil dari tahapan analisis menjadi bahan dasar pembuatan modul Braille pendidikan kesehatan repoduksi.

Perencanaan penyusunan modul Braille berisi halaman cover sebagai judul modul. Kata pengantar yang berisi ucapan terimakasih serta penjabaran secara umum pendidikan kesehatan reproduksi. Daftar isi sebagai petunjuk kemudian ada empat bab materi pembahasan pendidikan kesehatan reproduksi yaitu latar belakang, tujuan umum dan tujuan khusus modul, manfaat, petunjuk penggunaan modul, ruang lingkup modul serta materi-materi yang telah dipilih sesuai dengan kurikulum 2013 yang telah disetujui oleh guru. Pada bagian akhir modul dilengkapi dengan rangkuman, evaluasi serta kunci jawaban untuk mempermudah siswa tunanetra belajar mandiri mengenai kesehatan repoduksi. Alat evaluasi yang digunakan dalam modul Braille berbentuk soal objektif agar siswa tunanetra mudah dalam mengunakan modul Braille yang telah dilengkapi dengan kunci jawaban agar siswa tunanetra bisa belajar mandiri.

Tahap Pengembangan :

Tahapan pengembangan dilakukan untuk memproduksi modul Braille pendidikan kesehatan reproduksi dengan dua versi yaitu versi awas sebanyak 52 halaman dan versi Braille sebanyak 128. Prosedur pembuatan modul braille pendidikan kesehatan reproduksi diawali dengan membuat softcopy di microsoft word kemudian softcopy diberikan ke percetakan huruf Braille. Softcopy yang telah tersedia akan dicetak menjadi huruf Braille dengan menggunakan DBT (Duxbury Braille Translation). Setelah dilakukan konveksi maka dapat dilakukan tahapan mencetak dengan menggunakan cetakan Braille kemudian pembuatan modul versi awas menggunakan aplikasi coreldraw X7. Sedangkan untuk cover modul awas maupun modul braille dibuat sama.

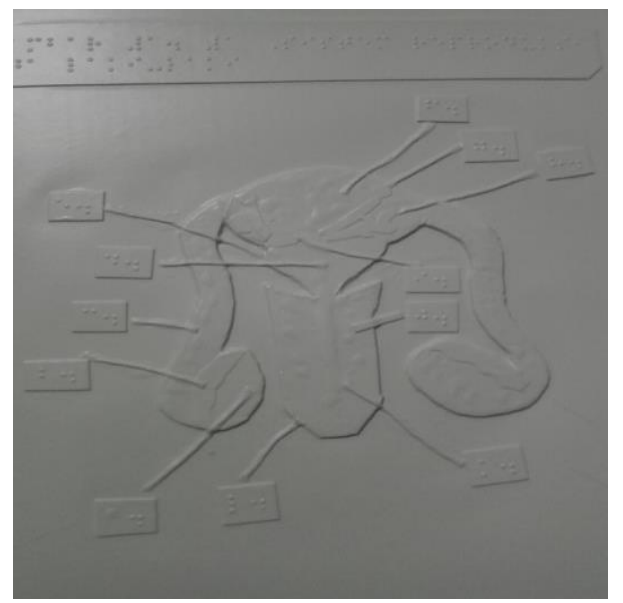

Gambar 1. alat reproduksi laki-laki pada modul Braille

Tahapan awal yang akan dilakukan yaitu pembuatan skema gambar, dengan menggunakan aplikasi careldraw. Tahapan setelah skema selesai maka selanjutnya membuat master (gambar timbul) yang dicetak dengan menggunakan thermoform (mesin pencetak gambar timbul). Tahapan selanjutnya setelah menyelesaikan pengembangan modul adalah menyusun instrumen penilaian. Penilaian validasi instrumen 
dilaksanakan oleh dosen pembimbing, ahli materi dan ahli media, guru bimbingan konseling, dan peer reviewer kemudian uji coba produk pada siswa kelas VII MTs Luar Biasa A Yaketunis Yogyakarta.

Tahap Evaluasi :

Evaluasi produk pada tahapan pengembangan ini dilaksanakan sebanyak 3 kali. Evaluasi awal dilakukan oleh dosen pembimbing berupa saran dan juga masukan terkait modul yang dikembangkan selanjutnya, evaluasi kedua dilakukan oleh ahli materi, ahli media, guru bimbingan konseling, peer reviewer kemudian, tahapan evaluasi ketiga dilakukan atas penilaian dan masukan dari siswa tunanetra sebagai pengguna modul Braille. Berikut hasil rata-rata perolehan validator:

Tabel 2. Hasil rata-rata validator

\begin{tabular}{|r|l|c|c|l|}
\hline No & \multicolumn{1}{|c|}{ Validator } & Rata-rata & Max & Kategori \\
\hline 1. & Ahli Materi & 76 & 80 & Sangat Baik \\
2. & Ahli Media & 54 & 60 & Sangat Baik \\
3. & Guru BK & 108 & 110 & Sangat Baik \\
4. & Peer reviewer & 99,33 & 110 & Sangat Baik \\
\hline
\end{tabular}

Perolehan hasil rata-rata ahli materi 76 dari skor maksimal 80 dengan kategori sangat baik. Rata-rata perolehan dari ahli media 54 dai skor maksimal 60 dengan kategori sangat baik. Guru bimbingan konseling memperoleh hasl rata-rata 108 dari skor maksimal 110, kemudian perolehan hasil rata-rata 99,33 dari skor maksimal 110 kategori sangat baik adalah Peer reviewer. Validator terakhir oleh siswa tunanetra yang menjadi pengguna produk modul Braille memperoleh hasil rata-rata 53 dai skor maksimal 60 dengan kategori sangat baik.

Saran dan masukan oleh dosen pembimbing yang telah direvisi dilanjutkn dengan melaksanakan validasi oleh ahli materi, ahli media, guru bimbingan konseling dan peer reviewer. Pada tahapan ini terdapat beberapan saran serta masukan yang diberikan oleh validator, guru BK dan peer reviewer. Revisi diantaranya berkaitan dengan materi yang lebih spesifik kepada remaja tunanetra, desain modul, gambar, dan beberapa penulisan yang masih salah. Uji ahli menggunakan tiga bentuk modul yaitu soft file pdf, modul versi awas dan modul versi Braille.

Kegiatan selanjutnya yang dilakukan adalah uji coba produk kepada siswa MTs Luar Biasa A Yaketunis Yogyakarta berjumlah 3 siswa hal ini dilakukan pada saat pandemi covid 19 sehingga terdapat batasan dalam melaksanakan uji coba produk. Uji coba dilakukan atas izin pihak sekolah dan pihak siswa yang berkenan unuk dikunjungi dengan syarat tetap menjaga protokol kesehatan. Fasilitas yang diberikan kepada siswa tunanetra berupa modul Braille mendapat tanggapan positif dari siswa tunanetra. Pada tahap uji coba produk siswa tunanetra antusias dalam membaca modul Braille kesehatan reproduksi. Saat observasi awal dilakukan pada pelajaran bimbingan koseling siswa lebih banyak melakukan diskusi dan tanya jawab dengan guru BK. Siswa terlatih mengutarakan pendapatnya dan mampu membisakan diri melakukan pertukaran pikiran dalam mengatasi masalah serta menghargai pendapat orang lain hal ini bertepatan dengan gagasan yang disampaikan oleh (Yamin \& Maisah, 2009) mengenai diskusi. Diskusi dilakukan oleh siswa tunanetra nantinya dapat mengambil rujukan dari modul Braille pendidikan kesehatan reproduksi agar arah diskusi menjadi terstruktur dan mampu mengurangi kesalahan informasi melalui internet.

Tabel 3. Penilaian dari Siswa Disabilitas Tunanetra

\begin{tabular}{|c|c|c|c|c|c|}
\hline No & Aspek & Skor Max & Skor & Presentase & Kategori \\
\hline 1 & Materi & 45 & 42 & $93,33 \%$ & Sangat Baik \\
3 & Penyajian & 30 & 27 & $90 \%$ & Sangat Baik \\
4 & Keterbacaan & 45 & 37 & $82,22 \%$ & Sangat Baik \\
& Grafika & 60 & 53 & $88,33 \%$ & Sangat Baik \\
\hline
\end{tabular}

Uji coba dilakukan kepada siswa tunanetra satu persatu dengan mendatangi rumah siswa tunanetra. Siswa tunanetra mempelajari modul Braille secara mandiri kemudian mengisi instrumen penilaian. Berdasarkan instrumen yang telah dibagikan kepada siswa tunanetra maka dapat disimpulkan bahwa penilaian yang diberikan memperoleh kategori sangat baik. Aspek pada instrumen terdapat aspek materi 
memperoleh hasil presentase $93,33 \%$, aspek penyajian menapatkan hasil presentase $90 \%$, kemudian aspek keterbacaan memperoleh hasil presenase $82,22 \%$ dan aspek grafika mendapatkan hasil presentase $88,33 \%$.

Gagasan oleh (Trianto, 2009) mengenai materi pelajaran akan bemakna jika materi belajar berdasarkan kehidupan mereka dan akan menemukan makna pada tahapan pembelajarannya maka, pelajaran akan terasa lebih menyenangkan. Materi-materi yang disajikan pada pengembangan modul Braille seputar keseharian serta kebutuhan siswa tunanetra. Berdasarkan hasil penelitian perlu diperhatikan manfaat dari produk yang dikembangkan selanjutnya adalah media Braille pendidikan kesehatan reproduksi dapat digunakan oleh guru bimbingan konseling dalam pembelajaran. Modul Braille pendidikan kesehatan reproduksi dikembangkan untuk bahan ajar guru dan bahan belajar siswa tunanetra. Pada pengembangan modul Braille lanjutan dapat menggunakan metode penilaian lain dengan menggunakan spss dan membandingkan penggunan modul Braille dan pengembangan dapat dilakukan dengan tema lain seperti spesifik pada bidang sosial remaja tunanetra.

\section{Conclusions}

Kebutuhan bahan belajar maupun bahan ajar dalam bentuk media Braille sebab menjadi salah satu cara penyampaian pengetahuan mengenai pendidikan kesehatan reproduksi bagi remaja tunanetra. Materi yang disajikan di dalam modul Braille pendidikan kesehatan reproduksi dipilih sesuai dengan kebutuhan remaja tunanetra dan sesuai dengan kurikulum 2013 pendidikan kesehatan reproduksi. Pengembangan modul Braille pendidikan kesehatan reproduksi dijabarkan dalam kompetensi inti (KI), kompetensi dasar (KD), tujuan pembelajaran, pencapaian siswa tunanetra dilanjutkan dengan isi materi pendidikan kesehatan reprduksi. Pengembangan modul Braille melalui beberapa tahapan yaitu tahapan analisis (kebutuhan, materi, kurikulum, karakteristik, intruksional), tahapan desain, tahapan pengembangan, tahapan evaluasi dan tahapan penilaian produk. Secara keseluruhan hasil perolehan presentase oleh validator dan siswa memperoleh hasil dengan kategori sangat baik, karena hasil presentase berada dalam penilaian interval yaitu $80 \%-100 \%$ dengan kategori sangat baik. Perolehan presenase dengan kategori sangat baik menjadi dasar modul Braille pendidikan kesehatan reproduksi bagi remaja tunanetra layak untuk digunakan untuk bahan ajar guru dan bahan belajar siswa tunanetra.

\section{Acknowledgments}

Peneliti banyak menghadapi hambatan dan kendala dalam penyelesaian tesis ini, tetapi dengan pertolongan-Nya dan motivasi serta dukungan dari berbagai pihak, peneliti dapat menyelesaikan karya tulis ini. Oleh karena itu, dengan segala kerendahan hati dan ketulusan hati penulis mengucapkan banyak terima kasih.

Terima kasihkkepada Ibu Rof'ah, M.S.W., M.A., Ph.D selaku pembimbing tesis, Terima kasih juga kepada Dr. Dra. Sari Rudiyati, M.Pd selaku ahli media dan ahli materi pengembangan modul pada penelitian ini. Terima kasih kepada seluruh keluarga besar peneliti yang telah memberikan doa, semangat dan dukungan baik secara moril dan materil, sehingga dapat memperoleh gelar Magister. Terima kasih kepada seluruh informan dalam penelitian ini, kepala sekolah, guru bimbingan konseling, guru IPA dan para siwa-siswi kelas IX MTs Luar Biasa-A Yaketunis Yogyakarta. Serta kepada peer reviewer mahasiswa Bimbingan dan Konseling Islam angkatan 2018, Program Interdisciplinary Islamic Studies.

\section{References}

Adegbenro, Caleb. A., Adeniyi, J. D., \& Oladepo, O. (2006). Effect of Training Programme on Secondary Schools Teachers' Knowledge and Attitude Towards Reproductive Health Education In Rural Schools Ile-Ife, Nigeria. African Journal of Reproductive Health, 10, No 03.

Ali, M., Ayaz Bhatti, M., \& Ushijima, H. (2004). Reproduksi Health Needs of Adolecent Males Rural Pakistan: An Exploratory Study. Tohoku J. Exp. Med, 204.

Awusabo-Asare, K., Biddlecom, A., Kumi-Kyereme, A., \& Patterson, K. (2006). Adolescent sexual and reproductive Health in Ghana: Results From the 2004 National Survey of Adolescents. Occasional Repport, 22.

Aziz, S. (2014). Pendidikan Seks Bagi Anak Berkebutuhan khusus. Vol II, No. 02.

Dubarstein Lindberg, L., Ku, L. gh ton, \& Sonenstein, F. (2000). Adolescents' Reports of Reproductive Health Education, 1988 and 1995: Vol. 32 (5). Family Planning Perspective.

Friend, M., \& Bursick, W. D. (2012). Including Student with Special Needs: A Practical Guide for Classroom Teacher (Sixth Edition). USA:Pearson.

Hakim, T. (2008). Belajar Secara Efektif. Niaga Swadaya.

Hermawan, I. (2019). Metodologi Penelitian Pendidikan Kuantitatif, Kualitatif \& Mixed Methode (I). Hidayatul Quran Kuningan. 
Indriastuti, F. (2015). Efektifitas Media Pembelajaran Audio Melalui Cerita Pendidikan Berkarakter Untuk Tunanetra Jenjang SMP. Media Cerdiktera, No. 01.

Li, P., Lau, Aga Mohd Jaladin, R., \& Sharil Abdullah, H. (2013). Understanding The Two Sides of Online Counseling and Their Ethical and Legal Ramifications. Procedia-Social and Behavior Sciences, 103.

Lukfiyanti, R. (2020). Pendidikan Agama Islam pada Keluarga Tunanetra di Kota Salatiga Tahun 2019. IAIN Salatiga.

Lutfi Ghazali, P. (2009). Pengmabangan Buklet Sebagai Media Pendidikan Kesehatan Reproduksi Pada Remaja Tunanetra. JKKI-Jurnal Kedokteran dan Kesehatan Indonesia, I, No. 1.

M. Denno, D., J. Hoopes, A., \& Chandra-Mouli, V. (2015). Effective Stategies To Provide Adolescent and Reproductive Health Services and to Increase Demand and Community Support. Journal of Adolescent Health, 56.

Mustafidah, S. (2018). Implementasi Pembelajaran Kesehatan Reproduksi untuk Mencegah Perilaku Seks Bebas pada Siswa Tunanetra Jenjang SMPLB-A TPA Jember. Journal Of Special Education, II, No. I.

Mutiara Mir'atannisa, I. (2017). Resiliensi Mahasiswa Tunanetra (Studi Kasus Terhadap Mahasiswa Tunanetra tidak dari Lahir di Fakultas Ilmu Pendidikan Universitas Negeri Yogyakarta). E-Journal Bimbingan dan Konseling.

Nasional, D. P. (2008). Panduan Pengembangan Bahan Ajar. Departemen Pendidikan Nasional Republik Indonesia.

Pamungkas, S. D., Debbiyantina, Kusumastuti, A., \& Winaney. (2019). Faktor-Faktor yang Berhubungan dengan Pengetahuan Kesehatan Reproduksi Remaja Tunanetra di Salah Satu Panti Sosial Jakarta Timur. The Southeast Asian Journal Of Midwifery, 5, No 01.

Rohani, I., Tobroni, Ishomuddin, \& Khozin. (2020). Pendidikan Agama Islam untuk Difabel (I). Gestalt Media.

Somantri, S. (2012). Psikologi Anak Luarbiasa. PT. Refika Aditama.

Speizer, I. S., Magnani, R. J., \& Colvin, C. E. (2003). The Effectiveness of Adolescent Reproductive Health Interventions in Developing Countries: A Review of the Evidence. Journal Of Adolescent Health, 33(5). https://doi.org/10.1016/S1054-139X(02)00535-9

Sudijono, A. (2010). Pengantar Statistik Pendidikan. Rajawali Pers.

Sugiyono. (2010). Metode Penelitian Kuantitatif, Kualitatif $R \& D$. Alfabeta.

Sumiati, E., Septian, D., \& Faizah, F. (2018). Pengembangan Modul Fisika berbasis Scientific Approach untuk Meningkatkan Keterampilan Proses Sains Siswa. Jurnal Pendidikan Fisika dan Keilmuan (JPFK), 4, No. 2.

Suparyanti, K., Kusmiyati, Y., \& Meilani, N. (2020). Pengaruh Media Booklet Braille Terhadap Peningkatan Pengetahuan Kesehatan Reproduksi pada Remaja Tunanetra di Asrama Yaketunis Yogyakarta Tahun 2019. Poltekes Kemenkes Yogyakarta.

Susilana, R., \& Riyana, C. (2007). Media Pembelajaran. CV. Wacana Prima.

Trianto. (2009). Mendesain Model Pembelajaran Inovatif-Progresif. Kencana.

Trumbul, A., Trumbul, R., Wehmeyer, M. L., \& Shogren, K. A. (2013). Exceptional Lives: Special Education In Today's Schools (Seventh Edition). USA:Pearson.

Wahba, M., \& Roudi-Fahimi, F. (2012). The Need For Reproductive Health Education In Schools In Egypt. Policy Brief.

Winarni, E. W. (2018). Teori dan Praktik Penelitian Kuantitatif, Kualitatif, PTK, R\&D (1 ed.). Bumi Aksara.

Yamin, M., \& Maisah, M. D. (2009). Manajemen Pembelajaran Kelas: Strategi Meningkatkan Mutu Pembelajaran. Gaung Persada. 